\title{
Evaluation of the shoreline effect of the marine energy farms in different coastal environments
}

\author{
Eugen Rusu $^{1, *}$ and Florin Onea ${ }^{1}$ \\ ${ }^{1}$ Department of Mechanical Engineering, “Dunarea de Jos"' University of Galati, Domneasca” Street, 47, Galati 800008, Romania
}

\begin{abstract}
The objective of the proposed work is to assess the possible effects on the shoreline dynamics of the marine energy farms. Three different coastal environments have been considered as case studies. The first area is located in the Portuguese continental nearshore at the European western coast of the Atlantic Ocean. The second in the Mediterranean Sea in the coastal environment of Sardinia Island and the third on the western side of the Black Sea in the Romanian nearshore. Besides the fact that, from a geographical point of view, the three areas targeted are located in very different zones, they represent also coastal environments with very different characteristics. A computational framework joining a spectral phase averaged wave model with a 1D parametric circulation model has been used. The numerical models are SWAN (acronym from Simulating Waves Nearshore) for the waves and NSSM (the Navy Standard Surf Model) for estimating the longshore currents. For each case study, the main characteristics of the environmental matrix have been analyzed first. Then, various transmission scenarios have been, designed considering also in each case different distances from the marine energy farm to the shoreline. A general conclusion of the proposed work is that the longshore currents are very sensitive to the presence of the marine energy farms and that is why such farms can also play an active role in coastal protection. Moreover, since it presents in parallel similar analyses for three coastal environments that have very different features, the present study provides a more comprehensive picture concerning the medium to long term impact on the shoreline dynamics of the future marine energy farms operating in the nearshore.
\end{abstract}

\section{Introduction}

The coastal areas are continuously shaped by the erosion and accretion processes which occur on various temporal and spatial scales. Although, these are common events which result from the natural and anthropogenic factors combination [1], during the recent years the beach erosion areas was significantly intensified, being estimated that only in Europe almost $15 \mathrm{~km}^{2}$ are lost into the sea (per year in 2010). In order to attenuate such coastal hazards, nearly $€ 3$ billion/year is allocated for this issue on a European level [2,3].

The wave action represents one of the most aggressive factors, if we consider that most of the wave energy dissipates in the surf area and the mechanical abrasion of the waves dislocate the sediment particles and carry them into the offshore areas. The breaking waves generate the longhsore currents which accelerate the erosion processes by transporting the particles in suspension along the coastline. The wave energy and longshore velocity significantly increase during the storm events, the beach cells being unable to regenerate in a reasonable period of time, especially if they show irregular features [4]. Various coastal protection systems emerged during time in order to reduce the coastal erosion, which include soft solutions (beach nourishment) or hard engineering, such as: sea walls and dikes, revetments or breakwaters [5]. These solutions require a high budget and may be considered to have limited efficiency, since they act on the effects of the erosion and do not tackle the source of the problem, which is the wave action [6].

In this case, a viable alternative comes from the renewable industry, more precisely from the wind and wave resources which are green energy and represent a sustainable source [7-9]. In terms of the coastal protection, better results are expected from the wave energy converters (WECs) developments which are capable to capture the wave energy from the offshore and nearshore areas. By deploying these generators on a wave farm configuration, it is possible to reduce more efficiently the wave heights and to avoid the regenerating effects of the wave fields, which may occur in the case of a single line breakwater.

Since most of the WECs include a connection to the seabed throughout a mooring system, this brings the opportunity to relocate the systems to other coastal sectors (if needed). Motivated by these aspects, the purpose of the present work will be to provide some insights about the effectiveness of a generic wave farm operating in various coastal environments.

\section{Methods and materials}

*Corresponding author: erusu@ugal.ro 
The wave evolution in the geographical space will be assessed by using the SWAN (Simulating Waves Nearshore) wave model, which represents a state-of-theart modeling tool based on the spectrum concept. This is capable to identify the sea state variation throughout the action balance equation, which is defined as [10]:

$$
\frac{\partial N}{\partial t}+\nabla x \cdot\left[\left(c_{g}+\stackrel{\rho}{U}\right) \cdot N\right]+\frac{\partial C_{\sigma} N}{\partial_{\sigma}}+\frac{\partial C_{\theta} N}{\partial_{\theta}}=\frac{S_{t o t}}{\sigma}
$$

where, the left side represents the kinematic part of the equation, while on the right side the source and sink terms are given. These are associated with the most relevant physical processes. The waves and longshore currents variation are assessed throughout the ISSM (Interface for SWAN and Surf Models) which combines the models SWAN with the NSSM (Navy Standard Surf Model) [11].

Three different target areas were considered for evaluation, as illustrated in Figure 1, where the SWAN computational domains are presented. An important objective of the current work will be to identify the generic farm influence taking into account various distances from the shore, in this case being considered two scenarios: A) farm at $\approx 1.5 \mathrm{~km}$ (denoted with F1.5) and $\mathrm{B}$ ) farm at $\approx 3 \mathrm{~km}(\mathrm{~F} 3)$.

The first case study is in the Portuguese coastal environment, more precisely close to the Leixoes harbor, north to the city of Porto [12]. A maximum depth of $50 \mathrm{~m}$ defines the left corner of this area, which covers a surface of $36 \mathrm{~km}^{2}$. A detailed evaluation of the wave variation in the vicinity of the shoreline comes from the two reference lines (L1 and L2) and throughout the four reference points (P1, P2, P3 and P4). A similar evaluation scheme will be used for all the areas taken into account. Going from an oceanic environment to an enclosed sea, Figure 1c presents a coastal sector close to the Sardinia Island, more exactly on the western side in the vicinity of Porto Ferro [13]. A bay defines this region, where the water depth does not exceed $100 \mathrm{~m}$. The Black Sea environment was also considered in Figure 1d, in this case being selected a sector in the Romanian nearshore (Mangalia) which is located at the southern extremity of this region [14]. This computational domain is defined by a 5 by $5 \mathrm{~km}$ length in $\mathrm{x}$ and $\mathrm{y}$ direction, reporting a maximum depth of $25 \mathrm{~m}$ and a curbed shoreline configuration.

The numerical simulations involve several absorption scenarios. The first one is associated to a moderate absorption (denoted with MA), which corresponds to a transmission coefficient of 0.8 and a reflection coefficient of 0.05 [12]. This means that the WEC line absorbs only $20 \%$ of the waves, while $5 \%$ of the waves are reflected. The second case study involves a highly absorbing configuration $(C t r=0.6 ; C r=0.08)$, which simulates an ideal scenario, since almost $40 \%$ of the incoming waves will be available for the power generation.

Each geographical area is defined by a particular wave climate, therefore we need to consider a reliable source of data to initiate the SWAN simulation. In this study it was considered the reanalysis wave database provided by the European Centre for Medium-range Weather Forecast [15], which corresponds to the 10-year interval 20072016. The most relevant wave parameters $(H s$-significant wave height, $T m$-wave period; Dir- wave direction) were processed from a grid defined by a spatial resolution of $0.75^{\circ} \times 0.75^{\circ}$ and considering a time resolution of four data per day (00-06-12-18 UTC). Table 1 presents the most relevant wave patterns, indicated in terms of the average and extreme values.
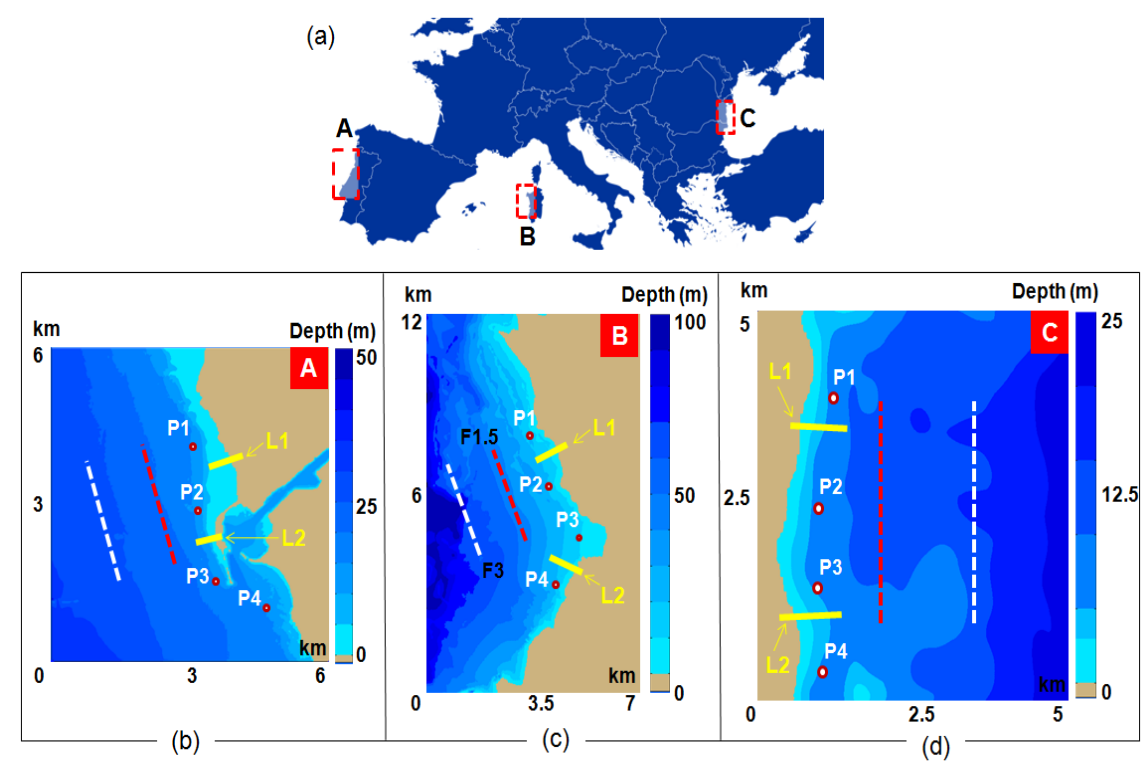

Figure 1. (a) Location of the three target areas and the computational domains considered for the SWAN simulations (b) Leixoes in the Portuguese nearshore, (c) Porto Ferro in the coastal environment of Sardinia Island and (c) Mangalia in the Romanian nearshore). In the background the bathymetry is presented while in the foreground the set-up of the wave farm scenario and the reference lines and points selected for the analysis. 
Table 1. Extreme wave conditions, according to the ECMWF data (time interval 2007-2016) in the vicinity of the three target areas (Leixoes located in the Portuguese nearshore, Porto Ferro in the coastal environment of Sardinia Island and Mangalia located in the Romanian nearshore).

\begin{tabular}{|c|c|c|c|c|c|}
\hline \multirow{2}{*}{ Site } & \multirow{2}{*}{ Conditions } & \multicolumn{3}{|c|}{ Wave parameters } & \multirow{2}{*}{ SWAN } \\
\cline { 3 - 5 } & & $\begin{array}{c}H s \\
(\mathrm{~m})\end{array}$ & $\begin{array}{c}\text { Tm } \\
(\mathrm{s})\end{array}$ & $\begin{array}{c}\text { Dir } \\
\left({ }^{\circ}\right)\end{array}$ & scenarios \\
\hline \multirow{2}{*}{ Leixoes } & Average & 1.6 & 8.1 & 288 & $5 \mathrm{~m}-13.6 \mathrm{~s}$ \\
& Extreme & 5 & 13.6 & - & $-288^{\circ}$ \\
\hline \multirow{2}{*}{$\begin{array}{c}\text { Porto } \\
\text { Ferro }\end{array}$} & Average & 0.9 & 4.9 & 232 & $5.4 \mathrm{~m}-9.5 \mathrm{~s}$ \\
\cline { 2 - 5 } & Extreme & 5.4 & 9.5 & - & $-232^{\circ}$ \\
\hline \multirow{2}{*}{ Mangalia } & Average & 0.6 & 4.1 & 148 & $3.5 \mathrm{~m}-7.7 \mathrm{~s}$ \\
\cline { 2 - 5 } & Extreme & 3.5 & 7.7 & - & $-148^{\circ}$ \\
\hline
\end{tabular}

As expected, the Leixoes site presents more consistent values indicating an average significant wave height of $1.6 \mathrm{~m}$ and a maximum value of $5 \mathrm{~m}$, with the mention that the Porto Ferro conditions present a maximum of 5.4 $\mathrm{m}$ while the average value is $0.9 \mathrm{~m}$.

For the Mangalia site the most common heights vary around the value of $0.6 \mathrm{~m}$, while during the extreme events a maximum of $3.5 \mathrm{~m}$ may occur. In terms of the wave direction, we observe that each target area is defined by a statistical value, which reflects the shoreline orientation and the direction from which the waves may occur. Taking into account that during the extreme events (ex: storms), the beach sectors are more affected by the erosion processes, only these extreme conditions will be further considered for evaluation (see Table 1).

\section{Results}

A first evaluation of the WEC influence is presented in Figure 2, considering also the scenario when both WEC lines $(\mathrm{F} 1.5+\mathrm{F} 3)$ will operate, as in the case of a wave farm configuration. For the no farm situation, it can be observed the distribution of the wave fields and the tendency of the waves to rotate as they enter in the surf area. The shielding effect induced by the farm is influenced by the line position according to the incident waves and shoreline orientation, being also influenced by the distance to the shore. In the case of the F3 scenario, the values from the interval $4-4.5 \mathrm{~m}$ seems to occur mainly in the southern part of the Leixoes harbor compared to F1.5 scenario.

The absorption property of the farm also plays a key role, which is revealed by the multiple wave fields that occur between the farm and the shoreline. The presence of the two WEC lines (MA set-up) seems to replicate the effects observed for the study F3-HA, with the mention that the shielding effect is noticed closer to the shoreline.

Figure 3 illustrates a similar distribution, considering this time for the western part of the Mediterranean Sea, where the waves are coming from the south-west sector, and more consistent variations occur in the case of the HA scenario. Figure 4 is focused on the Mangalia region, where in general the central part reports wave conditions of 2-3 m compared to the lower-right corner where maximum heights of $4 \mathrm{~m}$ may occur.

For this environment, the F1.5 WEC line influence seems to count more. From the maps representing the spatial variations of the wave height we can estimate the size of the shielding and the beach sectors which is influenced, but it is difficult to estimate the intensity of this effect. Table 2 illustrates the $H s$ variations for the no farm situation (in meters) and for the WEC influence.
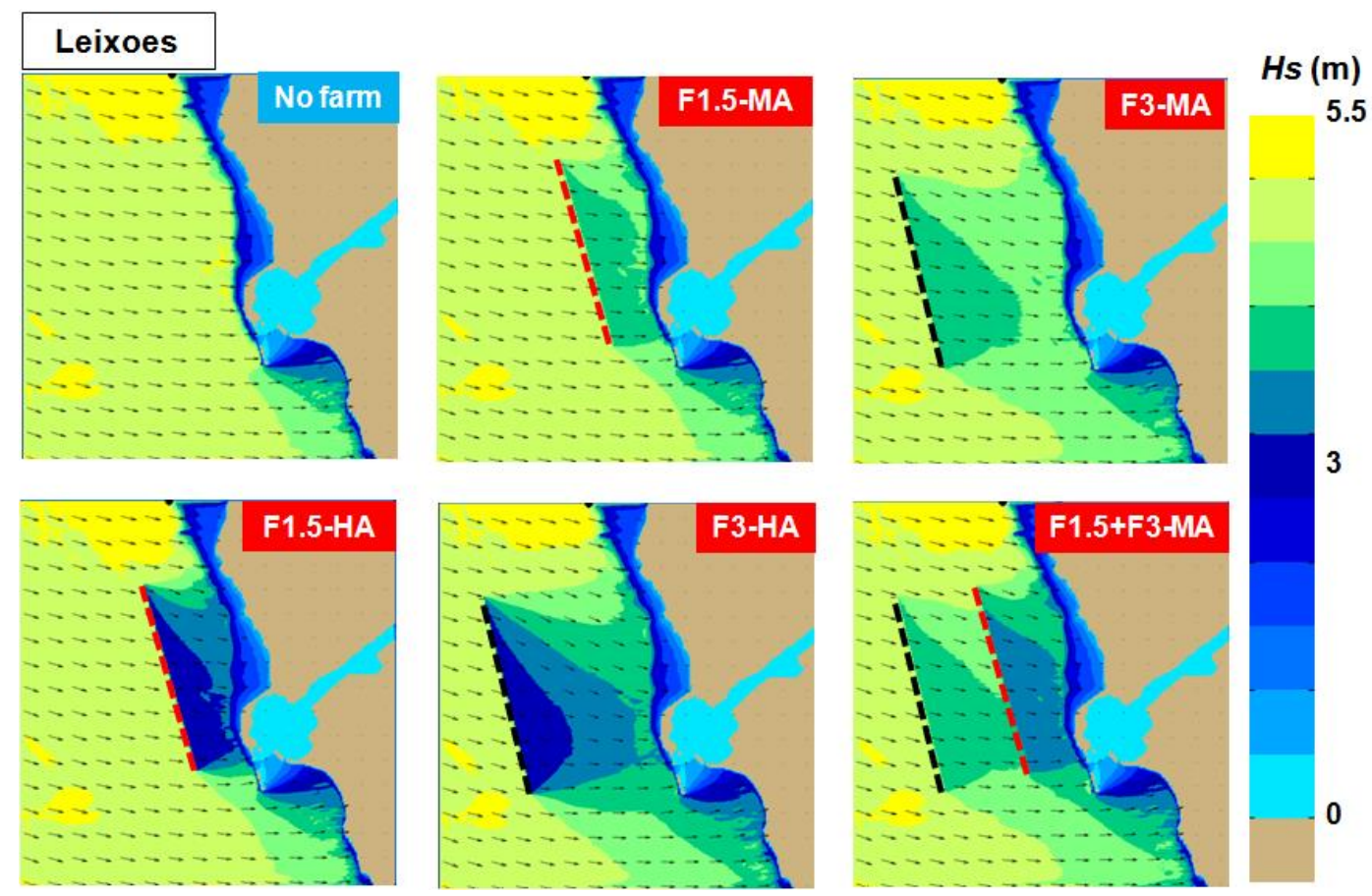

Figure 2. Evaluation in the geographical space (significant wave height scalar fields and wave vectors) based on the influence of the generic farm operating in the Leixoes region (Portugal) under extreme conditions. 
According to these variations (in \%), the significant wave heights will be reduced, regardless the case studies considered for evaluation. For the Leixoes area, more important values occur in the vicinity of the reference points $\mathrm{P} 1$ and $\mathrm{P} 2$, in the case of the F1.5-HA scenario ( $\max 35.93 \%$ ). The two-line configuration may represent a second option for the coastal protection revealing a maximum of $28.2 \%$ close to the point P2. From the MA results, it seems that a farm located at $1.5 \mathrm{~km}$ will be more effective than a project located in the offshore region.
The Sardinia Island case study (Porto Ferro) reveals a similar trend, where a maximum attenuation of $37.3 \%$ is accounted by the F1.5 configuration. A two-line wave farm may reduce the waves with $27.57 \%$, being followed by the F1.5 line with $19.14 \%$. For the Mangalia region, which represents a marine environment defined by moderate wave resources, seems that the best protection is provided by a farm located close to the shore (at 1.5 $\mathrm{km})$. Another viable solution will be to consider a twoline wave farm, which may attenuate the waves between the reference points $\mathrm{P} 1$ and $\mathrm{P} 3$ with almost $10 \%$.

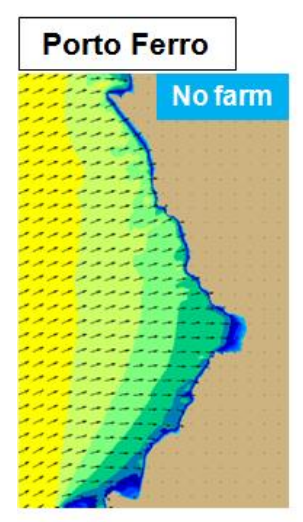

F1.5-HA

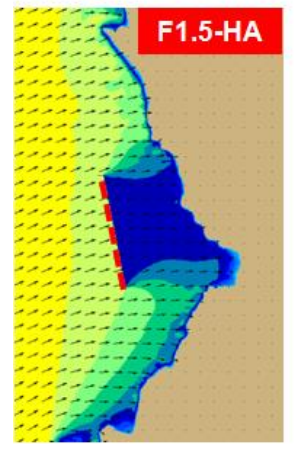

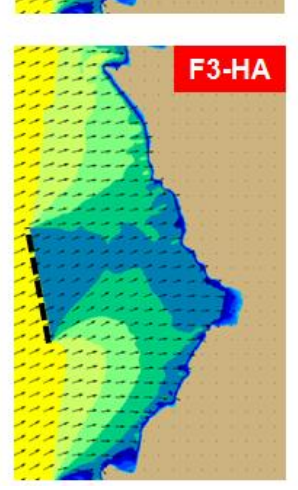

F1.5-MA

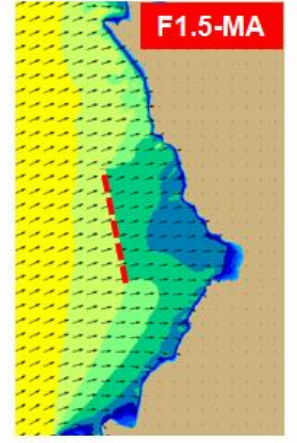

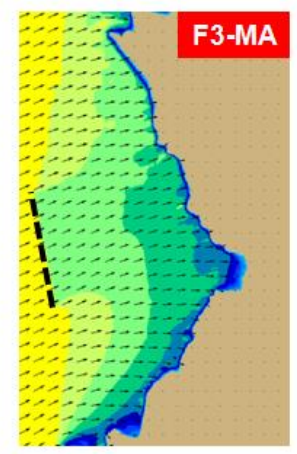

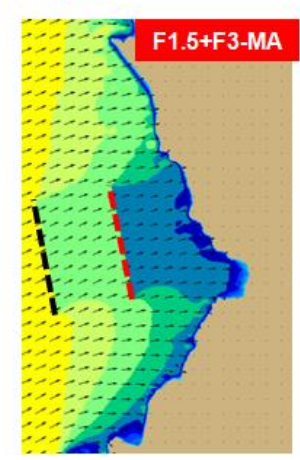

$H s(\mathrm{~m})$

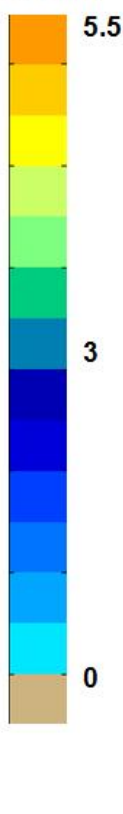

Figure 3. Evaluation in the geographical space (significant wave height scalar fields and wave vectors) based on the influence of the generic farm operating in the Porto Ferro region (Sardinia Island) under extreme conditions.

Table 2. Variation of the $H s$ values (in \%) in the presence of the wave farm, where: F1.5-wave farm located at $1.5 \mathrm{~km}$ from the shore; F3-wave farm located at $3 \mathrm{~km}$ from the shore; MA - moderate absorption; HA-high absorption. With bold font the values higher than $10 \%$, are indicated while with underline font the values exceeding $20 \%$ are marked.

\begin{tabular}{|c|c|c|c|c|c|c|c|}
\hline Site & & No farm (m) & F1.5-MA (\%) & F3-MA (\%) & F1.5-HA (\%) & F3-HA (\%) & $\begin{array}{c}\text { Two lines-MA } \\
(\%)\end{array}$ \\
\hline \multirow{4}{*}{ Leixoes } & $\mathrm{P} 1$ & 4.71 & 14.5 & 9.47 & 28.44 & 18.3 & 22.32 \\
\hline & $\mathrm{P} 2$ & 4.59 & 17.49 & 10.69 & $\overline{35.93}$ & 21.96 & 28.2 \\
\hline & P3 & 4.65 & 6.41 & 9.60 & 10.23 & $\overline{17.12}$ & 14.53 \\
\hline & P4 & 3.82 & 1.59 & 5.43 & 2.431 & 10.18 & 6.65 \\
\hline \multirow{4}{*}{$\begin{array}{l}\text { Porto } \\
\text { Ferro }\end{array}$} & $\mathrm{P} 1$ & 4.26 & 7.53 & 9.16 & 13.72 & 16.42 & 15.25 \\
\hline & $\mathrm{P} 2$ & 4.25 & 19.14 & 10.9 & $\underline{37.3}$ & 20.11 & 27.57 \\
\hline & P3 & 3.73 & 10.12 & 7.30 & $\overline{18.84}$ & $\overline{13.53}$ & 15.37 \\
\hline & $\mathrm{P} 4$ & 3.78 & 1.25 & 4.60 & 2.091 & 8.161 & 5.454 \\
\hline \multirow{4}{*}{ Mangalia } & $\mathrm{P} 1$ & 1.85 & 5.48 & 3.36 & 17.33 & 8.642 & 11.12 \\
\hline & $\mathrm{P} 2$ & 2.02 & 7.56 & 4.14 & $\underline{22.2}$ & 9.912 & 13.7 \\
\hline & P3 & 1.84 & 5.97 & 2.32 & 14.35 & 6.537 & 10.01 \\
\hline & $\mathrm{P} 4$ & 1.08 & 1.44 & 1.02 & 4.227 & 2.642 & 3.162 \\
\hline
\end{tabular}



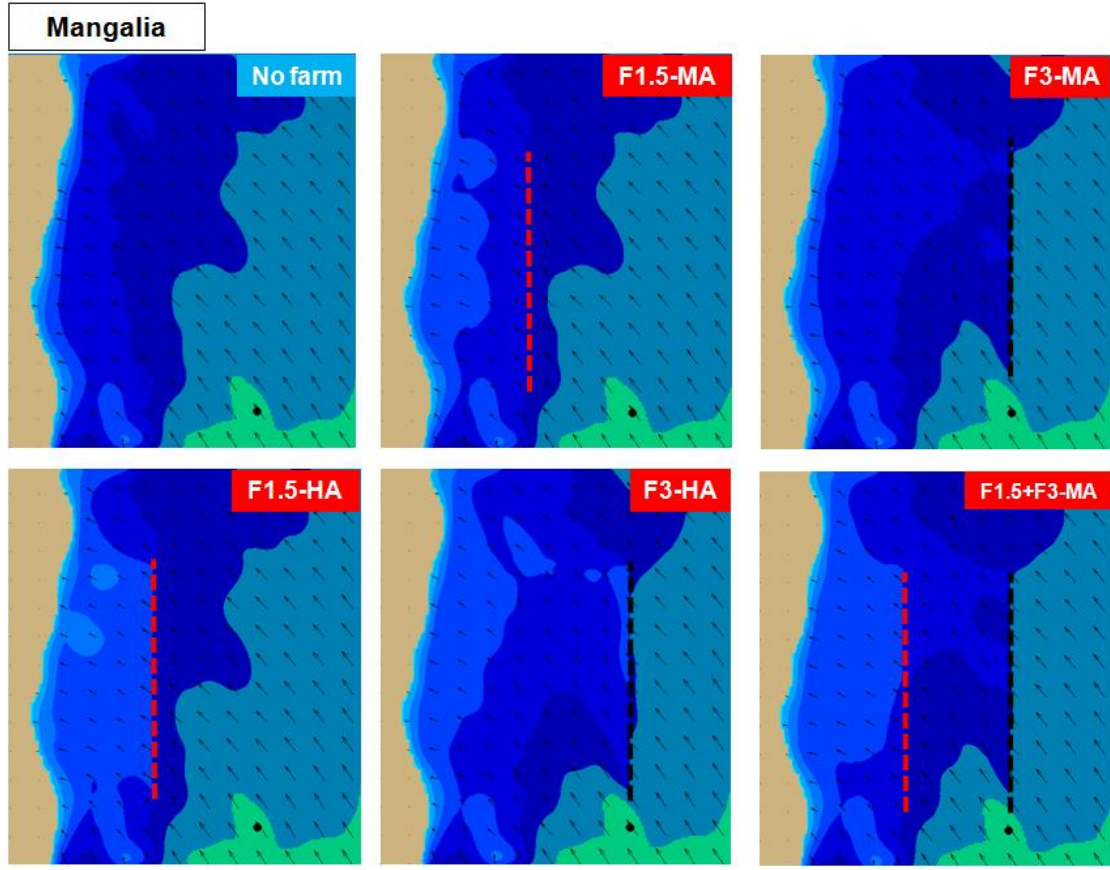

\section{Hs (m)}
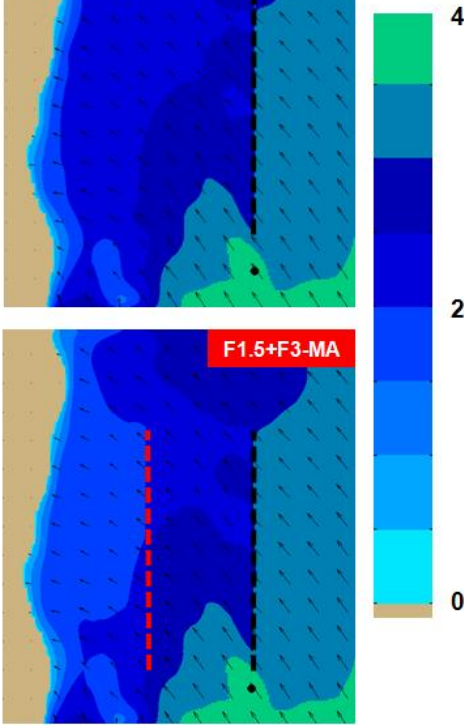

2

Figure 4. Evaluation in the geographical space (significant wave height scalar fields and wave vectors) based on the influence of the generic farm operating in the Mangalia region (Romanian nearshore) under extreme conditions.

Besides the significant wave height, the wave direction represents another important factor for the coastal erosion, since indicates the direction from where the beach sector will be more vulnerable. In the presence of an obstacle (such as the wave farm is) the initial direction may be shifted, and this variation is illustrated in Table 3. The variations reveal positive or negative values, reporting this time more important value for the Mangalia sector, where a maximum of 5.88 may occur close to the reference point P3 in the case of the F1.5-HA. In general, higher fluctuations may occur in the case of the two-line configuration with high absorption.

In the vicinity of the coastline, the longshore currents may change the balance between the accretion and erosion processes by influencing the flux of the sediment transport. In this respect, Figure 5 illustrates the profile of the longshore currents along the reference lines L1 and L2, from which it can be observed that in some cases (L1-Porto Ferro and L1-Mangalia) the presence of the
WEC lines reduces the distance to the shore. For example, in the case of Mangalia (no farm situation) the profile reveals a total length of $400 \mathrm{~m}$, which may decrease until $250 \mathrm{~m}$ in the F1.5-HA. For the Leixoes region, we can notice that the WEC influence increases the current velocity from $0.5 \mathrm{~m} / \mathrm{s}$ (no farm situation) to a value located close to $2 \mathrm{~m} / \mathrm{s}$ (F3-HA).

Table 4 presents the maximum current velocity, for all the areas targeted and the reference lines considered. In the case of the case studies Leixoes and Porto Ferro, we can notice that for the no farm scenario the current velocity is insignificant $(\approx 0 \mathrm{~m} / \mathrm{s})$, gradually increasing in magnitude according to the selected WEC configuration. Although Porto Ferro and Mangalia represent semi-enclosed basins, they indicate much higher value for the velocity of the nearshore currents than in the case of the Leixoes area, indicating maximum of $1.74 \mathrm{~m} / \mathrm{s}$ and $1.29 \mathrm{~m} / \mathrm{s}$ respectively.

Table 3. Variation of the mean wave direction (Dir parameter in \%), where with the bold font the negative variations in relationship with the no farm situation are indicated.

\begin{tabular}{|c|c|c|c|c|c|c|c|}
\hline Site & & No farm $\left({ }^{\circ}\right)$ & F1.5-MA (\%) & F3-MA (\%) & F1.5-HA (\%) & F3-HA (\%) & $\begin{array}{c}\text { Two lines-MA } \\
(\%)\end{array}$ \\
\hline \multirow{4}{*}{ Leixoes } & $\mathrm{P} 1$ & 272.5 & -1 & -1.32 & -2.67 & -2.90 & -2.39 \\
\hline & $\mathrm{P} 2$ & 275.2 & 0.29 & -0.63 & -0.11 & -1.72 & -0.38 \\
\hline & $\mathrm{P} 3$ & 265.5 & 1.48 & 1.42 & 2.45 & 2.74 & 2.87 \\
\hline & P4 & 257.3 & 0.37 & 1.10 & 0.56 & 2 & 1.43 \\
\hline \multirow{4}{*}{$\begin{array}{l}\text { Porto } \\
\text { Ferro }\end{array}$} & $\mathrm{P} 1$ & 240.8 & -1.48 & -0.95 & -3.01 & -1.93 & -2.50 \\
\hline & $\mathrm{P} 2$ & 250.1 & -0.22 & 0.35 & -0.56 & 0.83 & 0.09 \\
\hline & $\mathrm{P} 3$ & 260.4 & 1.06 & 0.71 & 2.29 & 1.48 & 1.76 \\
\hline & $\mathrm{P} 4$ & 258.2 & 0.37 & 1 & 0.63 & 1.85 & 1.28 \\
\hline \multirow{4}{*}{ Mangalia } & $\mathrm{P} 1$ & 112.3 & 0.61 & -1.06 & 1.77 & -2.06 & 0.14 \\
\hline & $\mathrm{P} 2$ & 106.6 & -1.13 & -2.33 & -3.34 & -5.09 & -3.41 \\
\hline & P3 & 91.92 & -1.82 & -1.24 & -5.88 & -2.01 & -2.77 \\
\hline & $\mathrm{P} 4$ & 110.9 & 0.09 & -1.12 & 0.25 & -2.37 & -0.72 \\
\hline
\end{tabular}



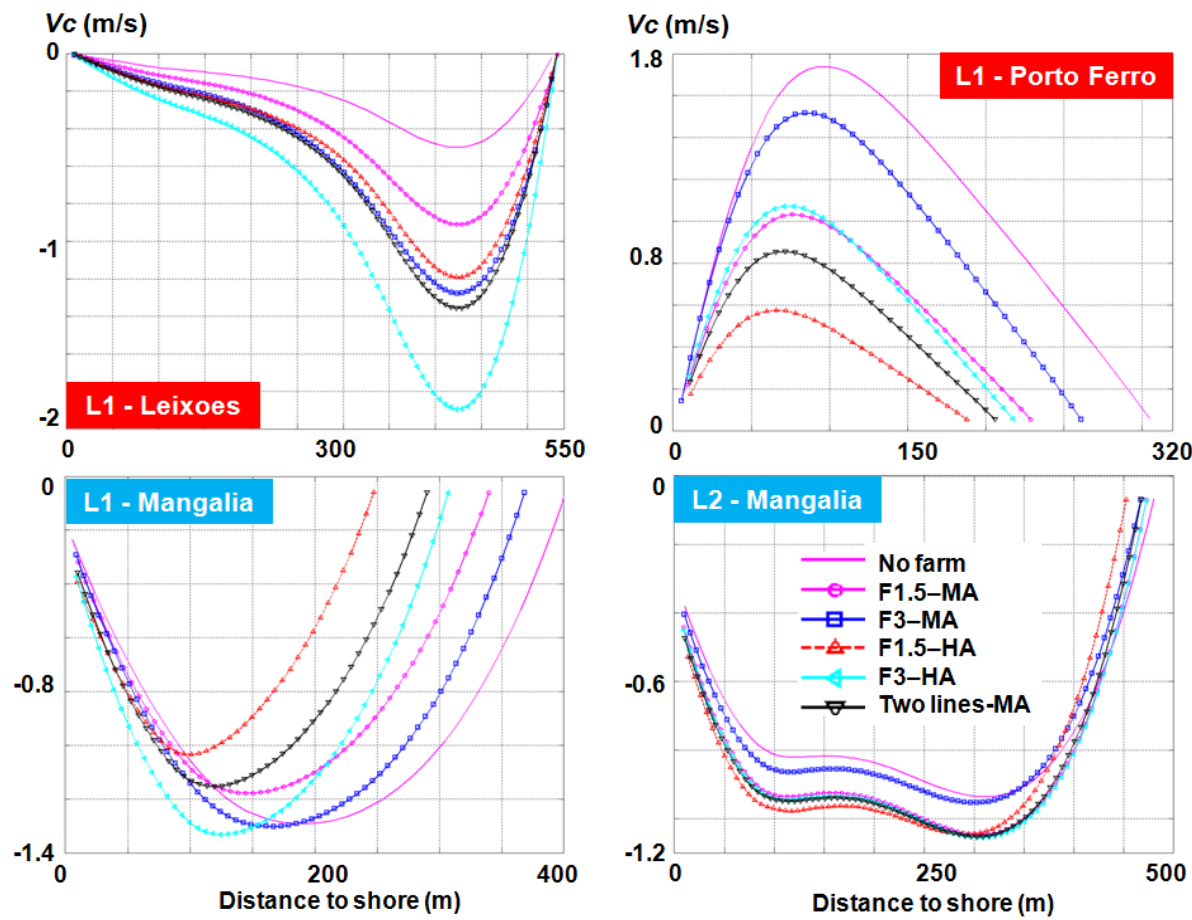

Figure 5. Nearshore current profiles indicating the impact of the generic wave farm in the vicinity of: line L1-Leixoes; line L2-Porto Ferro; lines L1 and L2 - Mangalia.

Table 4. Values of the maximum current velocities $(V c \max$ in $\mathrm{m} / \mathrm{s})$ reported in the presence of the wave farms in the three target areas taking into account.

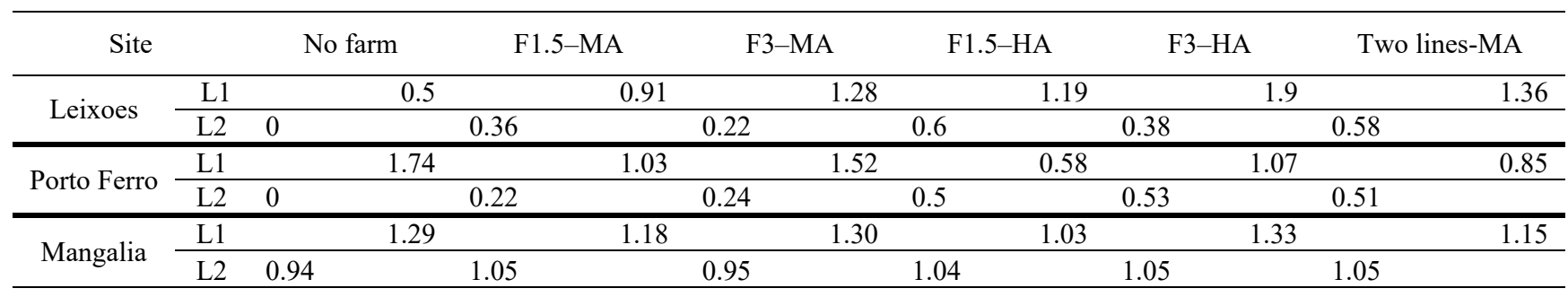

\section{Conclusions}

In the present work some insights were provided regarding the coastal variations induced by various WEC configurations which may operate in different coastal environments. For the Leixoes region (Portugal) it was noticed a significant attenuation of the waves, which is associated with an increase of the current velocity from zero to $0.58 \mathrm{~m} / \mathrm{s}$ (line L2). For this region all the configurations defined by a high absorption property seem to be efficient, of which can be added the two-line configuration. A similar trend is observed in the Porto Ferro environment, with the mention that the current velocity decreases along the line L1 and gradually increases along the L2. For Mangalia, more consistent results may be reported in the case of a single WEC line located close to the shore (F1.5-HA), while a two line configuration may be also considered for implementation.

Finally, it can be mentioned that the coastal erosion represents a serious threat to the beach stability and the emerging of WEC technology may offer additional opportunities for the coastal protection.

\section{Acknowledgements}

This work was carried out in the framework of the research project REMARC (Renewable Energy extraction in MARine environment and its Coastal impact), supported by the Romanian Executive Agency for Higher Education, Research, Development and Innovation Funding - UEFISCDI, grant number PN-IIIP4-IDPCE-2016-0017. The ERA-Interim data used in this study have been obtained from the ECMWF data server.

\section{References}

1. M. Lopez, J.L. Pagan, I. Lopez, L. Aragones, A.J. Tenza-Abril, J. Garcia-Barba, Factors influencing the retreat of the coastline. International Journal of Computational Methods and Experimental Measurements 5, 741-649 (2017). 
2. CONSCIENCE, Coastal erosion control based on the concept of sediment cells. Deltares, the Netherlands (2010).

3. EUROSION, A guide to coastal erosion management practices in Europe: lessons learned. National Institute of Coastal and Marine Management of the Netherlands (2004).

4. R. Davidson-Arnott, An introduction to coastal processes and geomorphology. Cambridge University Press (2010).

5. A.T. Williams, A. Giardino, E. Pranzini 2016. Canons of Coastal Engineering in the United Kingdom: Seawalls/Groynes, a Century of Change? Journal of Coastal Research 32-5, 1196-1211 (2016).

6. EUROSION, Living with coastal erosion in Europe sediment and space for sustainability. European Commission, ISBN 92-894-7496-3 (2004).

7. E. Rusu, F. Onea, Estimation of the wave energy conversion efficiency in the Atlantic Ocean close to the European islands. Renewable Energy 85, 687703 (2016).

8. F. Onea, R. Alina, E. Rusu, Evaluation of the wind energy potential in the coastal environment of two enclosed seas. Advances in Meteorology, doi:10.1155/2015/808617 (2015).

9. L. Rusu, F. Onea, The performance of some state-ofthe-art wave energy converters in locations with the worldwide highest wave power. Renewable and Sustainable Energy Reviews 75, 1348-1362 (2017).

10. SWAN, Scientific and technical documentation (SWAN Cycle III version 41.01A). Delft University of Technology (2015).
11. D.C. Conley, E. Rusu, The middle way of surf modeling. In: Proceedings of the 30th International Conference on Coastal Engineering, ICCE 2006, 2-9 September. San Diego, USA: World Scientific Pub Co Inc, Coastal Engineering, 1053-1065 (2006).

12. F. Onea, E. Rusu, The expected efficiency and coastal impact of a hybrid energy farm operating in the Portuguese nearshore. Energy 97, 411-423 (2016).

13. F. Onea, L. Rusu, Coastal impact of a hybrid marine farm operating close to Sardinia Island. OCEANS'15 MTS/IEEE GENOVA 18-21 May 2015 Genova, Italy (2015).

14. A.T. Zanopol, F. Onea, E. Rusu, Longshore curents evaluation along the Romanian Black Sea coast. 14th International Multidisciplinary Scientific Geoconference (SGEM) Location: Albena, Bulgaria Date: 17-26 June, 2, 637-644 (2014).

15. European Centre for Medium-Range Weather Forecasts (ECMWF), IFS Documentation - Cy31r1, Operational implementation. Part VII: ECMWF wave mode. European Centre for Medium-Range Weather Forecasts, Shinfield Park, Reading, England (2006). 